Article

\title{
Solid base catalysts derived from Ca-M-Al (M = Mg, La, Ce, Y) layered double hydroxides for dimethyl carbonate synthesis by transesterification of methanol with propylene carbonate
}

\author{
Yunhui Liao a,b, Feng Li ${ }^{\text {a,* }}$, Xin Dai a,b, Ning Zhao a,c, Fukui Xiao a,c,\# \\ a State Key Laboratory of Coal Conversion, Institute of Coal Chemistry, Chinese Academy of Sciences, Taiyuan 030001, Shanxi, China \\ b University of Chinese Academy of Sciences, Beijing 100049, Shanxi, China \\ c National Engineering Research Center for Coal-Based Synthesis, Taiyuan 030001, Shanxi, China
}

\section{A R T I C L E I N F O}

\section{Article history:}

Received 11 July 2017

Accepted 15 August 2017

Published 5 November 2017

\section{Keywords:}

Ca-M-Al layered double hydroxide

Solid base

Transesterification

Dimethyl carbonate

\begin{abstract}
A B S T R A C T
Composite solid base catalysts derived from Ca-M-Al (M = Mg, La, Ce, Y) layered double hydroxides (LDH) were synthesized, characterized and applied to the transesterification of methanol with propylene carbonate. X-ray diffraction analyses of the catalysts show that all of the catalysts were in the form of composite oxides. Compared with the Ca-Al LDH catalyst, the specific surface areas and pore volumes of the catalysts were increased with the introduction of $\mathrm{Mg}$, $\mathrm{La}$ or $\mathrm{Ce}$. The catalytic performance of these catalysts increases in the order of Ca-Y-Al $<\mathrm{Ca}-\mathrm{Al}<\mathrm{Ca}-\mathrm{Ce}-\mathrm{Al}<\mathrm{Ca}-\mathrm{La}-\mathrm{Al}<\mathrm{Ca}-\mathrm{Mg}$-Al, which is consistent with the total surface basic amounts of these materials and the formation of especially strong basic sites following modification with Mg and La. The Ca-Mg-Al catalyst shows the highest $(\mathrm{Ca}+\mathrm{Mg}): \mathrm{Al}$ atomic ratio, indicating that it likely contains more unsaturated $\mathrm{O}^{2-}$ ions, providing it with the highest concentration of very strong basic sites. The recyclability of these catalysts is improved following the addition of $\mathrm{Mg}$, $\mathrm{La}$, Ce or $\mathrm{Y}$, with the Ca-Mg-Al maintaining a high level of activity after ten recycling trials. X-ray diffraction analyses of fresh and used Ca-Mg-Al demonstrate that this catalyst is exceptionally stable, which could be of value in practical applications related to heterogeneous catalysis.
\end{abstract}

(C) 2017, Dalian Institute of Chemical Physics, Chinese Academy of Sciences. Published by Elsevier B.V. All rights reserved.

\section{Introduction}

As the result of increasing interest in environmental protection, and because of associated governmental regulations, so-called green chemistry syntheses have received significant attention. Dimethyl carbonate (DMC) is a commonly used and environmentally benign building block in fine chemistry due to its useful chemical properties and low toxicity [1], and can be employed as a methylation or carbonylation reagent in place of the more hazardous substances phosgene and dimethyl sulfate [2]. DMC can also serve as an effective gasoline additive because of its high octane value [3], and is used as a monomer for the synthesis of polycarbonate resins [4].

Various methods has been developed for the synthesis of DMC, including the oxidative carbonylation of methanol $[5,6]$, the transesterification of methanol with cyclic carbonates [7-10], the alcoholysis of urea [11-13] and direct synthesis from carbon dioxide and methanol [14-16]. Among these, the

\footnotetext{
* Corresponding author. Tel: +86-351-4049612; Fax: +86-351-4046129; E-mail: lifeng2729@sxicc.ac.cn

\# Corresponding author. Tel: +86-351-4041153; Fax: +86-351-4046129; E-mail: xiaofk@sxicc.ac.cn

This work was supported by the Natural Science Foundation of Shanxi Province (201601D102006) and the Key Science and Technology Program of Shanxi Province, China (MD2014-09, MD2014-10).

DOI: 10.1016/S1872-2067(17)62898-5 | http://www.sciencedirect.com/science/journal/18722067 | Chin. J. Catal., Vol. 38, No. 11, November 2017
} 
transesterification of methanol with propylene carbonate (PC) is a promising route with the advantages of minimal potential for equipment corrosion, a high degree of safety and good yields $[17,18]$. It has been determined that basic catalysts are effective for this reaction [19], and metal oxides are of particular interest due to their various advantages, such as high activity and ease of recycling during continuous processing [10, 20-23]. Calcium oxide exhibits good catalytic activity but poor stability [9,24], and so the use of multi-metal composite oxides that facilitate the dispersion of $\mathrm{CaO}$ and increase the interactions of metals to prevent leaching has been proposed [9].

Layered double hydroxides (LDHs) have the general formula $\left[\mathrm{M}^{2+}{ }_{1-x} \mathrm{M}^{3+}{ }_{x}(\mathrm{OH})_{2}\right]^{x+}\left[\left(\mathrm{A}^{n-}\right)_{x / n}\right]^{x-} \cdot m \mathrm{H}_{2} \mathrm{O}$, where $\mathrm{M}^{2+}$ and $\mathrm{M}^{3+}$ represent divalent and trivalent metals and $\mathrm{A}^{n-}$ is an exchangeable interlayer anion [25]. Following the calcination of these materials, metal oxides with homogeneously dispersed $\mathrm{M}^{2+}$ and $\mathrm{M}^{3+}$ ions and adjustable acid-base properties are obtained [26]. Over the past several years, LDHs have been used in a wide array of practical applications in heterogeneous catalysis [26,27], adsorption [28], pharmaceuticals [29], photochemistry and electrochemistry [25,30]. Recently, studies have demonstrated that calcined Mg-Al, Ca-Al and Ca-Mg-Al LDHs are effective and stable transesterification catalysts [31-34]. Moreover, the introduction of basic rare earth elements (La, Ce or $\mathrm{Y}$ ) into these materials can modify the basic sites and thus modulate the basicity of the catalyst [35].

In the present work, the basic metals $\mathrm{Mg}$, $\mathrm{La}, \mathrm{Ce}$ and $\mathrm{Y}$ were inserted into Ca-Al LDHs and the corresponding mixed oxides were obtained by calcination. The catalytic activities of these new materials were subsequently assessed during the transesterification of methanol with PC. The effects of these metals on the physicochemical properties of the as-prepared mixed oxides were also investigated using X-ray diffraction (XRD), thermogravimetry-differential thermogravimetry (TG-DTG), infrared (IR) spectroscopy, X-ray photoelectron spectroscopy (XPS), inductively coupled plasma-optical emission spectroscopy (ICP-OES), Brunauer-Emmett-Teller (BET) surface area analyses, and $\mathrm{CO}_{2}$-temperature programmed desorption (TPD) and Hammett titration data. In this manner, a more comprehensive relationship between the catalytic activities of these materials and their physicochemical properties was developed.

\section{Experimental}

\subsection{Catalyst preparation}

Ca-M-Al (M = Mg, La, Ce or Y) LDHs were synthesized using a co-precipitation method. Typically, the appropriate amounts of metal chlorides (employing a $(\mathrm{Ca}+\mathrm{M}) / \mathrm{Al}$ molar ratio of 2 and a Ca/M molar ratio of 3) were dissolved in $100 \mathrm{~mL}$ distilled water to produce solution $\mathrm{A}$. The required quantity of $\mathrm{NaOH}$ was also dissolved in $100 \mathrm{~mL}$ distilled water to give solution $\mathrm{B}$. Subsequently, the two solutions were added dropwise by peristaltic pump to $250 \mathrm{~mL}$ of a water/ethanol solution having a water/ethanol volume ratio of 2:3, with vigorous stirring at $333 \mathrm{~K}$ under $\mathrm{N}_{2}$ while maintaining the $\mathrm{pH}$ at 10 , followed by stirring under the same conditions for $24 \mathrm{~h}$. The precipitate was removed by filtration and washed with deionized water until the wash water showed a $\mathrm{pH}$ of 7 , then dried under vacuum at $353 \mathrm{~K}$ and calcined at $1073 \mathrm{~K}$ under $\mathrm{N}_{2}$ for $6 \mathrm{~h}$. The precursors and calcined catalysts are designated herein as M-CAP and M-CA, respectively.

A pure Ca-Al LDH (with a Ca/Al molar ratio of 2) was synthesized using the same method described above, and the precursor and calcined catalyst are designated as CAP and CA, respectively. A mixture of $\mathrm{CaO}$ and $\mathrm{Al}_{2} \mathrm{O}_{3}$ was also prepared by mechanical mixing with a $\mathrm{Ca} / \mathrm{Al}$ molar ratio of 2 and is designated as CA-mixing.

\subsection{Characterization of catalysts}

XRD data were acquired with a D8 Advance (Bruker, Germany) diffractometer, using $\mathrm{Cu} K_{\alpha}(1.5406 \AA)$ radiation at $40 \mathrm{kV}$ and $50 \mathrm{~mA}$. The scan rate was $3^{\circ} / \mathrm{min}$ in the $2 \theta$ range of $5^{\circ}-80^{\circ}$. TG-DTG analyses were performed using a Rigaku TG 8120 instrument, heating each sample at $10 \mathrm{~K} / \mathrm{min}$ from room temperature to $1173 \mathrm{~K}$ under $\mathrm{N}_{2}$. Fourier transform IR (FT-IR) spectra were acquired with a Nicolet Nexus 470 FT-IR spectrophotometer over the range of 4000-400 $\mathrm{cm}^{-1}$, summing 64 scans for each spectrum and with a resolution of $2 \mathrm{~cm}^{-1}$. XPS data were acquired using an AXIS ULTRA DLD spectrometer with monochromatic Al $K_{\alpha}(1486.8 \mathrm{eV})$ radiation under ultrahigh vacuum. The binding energy (BE) values were calibrated internally using the $\mathrm{C} 1 \mathrm{~s}$ peak with $\mathrm{BE}=284.8 \mathrm{eV}$. The experimental error was within $\pm 0.1 \mathrm{eV}$. Elemental chemical analysis was performed using ICP-OES with a Thermo iCAP 6300 instrument.

The BET specific surface areas and pore volumes of these materials were determined with a Micromeritics Tristar II 3020. $\mathrm{CO}_{2}$-TPD data were acquired using a Builder PCA-1200 chemical adsorption instrument. Each sample was pretreated in a He flow at $1073 \mathrm{~K}$ for $1 \mathrm{~h}$ and then cooled to room temperature. $\mathrm{CO}_{2}$ was adsorbed at room temperature for $30 \mathrm{~min}$ at 40 $\mathrm{mL} / \mathrm{min}$, after which a He flow was initiated to purge residual $\mathrm{CO}_{2}$ for $30 \mathrm{~min}$. The desorption was performed at a heating rate of $10 \mathrm{~K} / \mathrm{min}$ from 323 to $1173 \mathrm{~K}$, using a thermal conductivity detector and $\mathrm{He}$ as the carrier gas.

Hammett indicators were employed to determine the basicity and base strength of each catalyst. Pre-treated catalyst specimens were dispersed in cyclohexane and titrated with a solution of benzoic acid in cyclohexane in the presence of Hammett indicators to determine the total basicity. The base strength $\left(H_{-}\right)$of each material was determined from the color change of various $\mathrm{pH}$ indicators after $12 \mathrm{~h}$, using phenolphthalein $\left(H_{-}=9.3\right)$, 2,4-dinitroaniline $\left(H_{-}=15.0\right)$, 4-nitroaniline $\left(H_{-}\right.$ $=18.4)$, 4-chloroaniline $\left(H_{-}=26.5\right)$ and diphenylmethane $\left(H_{-}=\right.$ $35.0)$.

\subsection{Catalytic tests}

All catalysts were activated at $1073 \mathrm{~K}$ under $\mathrm{N}_{2}$ for $1 \mathrm{~h}$ prior to catalytic trials in a glass batch reactor equipped with a spiral condenser at $333 \mathrm{~K}$. Following each reaction, the product was centrifuged, filtered and analyzed with a gas chromatograph 
equipped with a flame ionization detector. A stoichiometric excess of methanol was used during these reactions, and the PC conversion, DMC selectivity and DMC yield were calculated by the following equations.

$$
\begin{gathered}
\mathrm{PC} \text { conversion }=\frac{m_{\mathrm{PC} 1} / M_{\mathrm{PC}}-m_{\mathrm{PC} 2} / M_{\mathrm{PC}}}{m_{\mathrm{PC} 1} / M_{\mathrm{PC}}} \times 100 \% \\
\mathrm{DMC} \text { selectivity }=\frac{m_{\mathrm{DMC}} / M_{\mathrm{DMC}}}{m_{\mathrm{PC} 1} / M_{\mathrm{PC}}-m_{\mathrm{PC} 2} / M_{\mathrm{PC}}} \times 100 \% \\
\mathrm{DMC} \text { yield }=\frac{m_{\mathrm{DMC}} / M_{\mathrm{DMC}}}{m_{\mathrm{PC} 1} / M_{\mathrm{PC}}} \times 100 \%
\end{gathered}
$$

Here, $m_{\mathrm{PC} 1}$ is the mass of PC in the feed, $m_{\mathrm{PC} 2}$ is the mass of $\mathrm{PC}$ in the product, $m_{\mathrm{DMC}}$ is the mass of DMC generated, $M_{\mathrm{PC}}$ is the molar mass of PC, and MDMC is the molar mass of DMC.

\section{Results and discussion}

\subsection{XRD analysis}

The XRD patterns of the CAP and M-CAP samples are shown in Fig. 1(a). It is evident that all samples had a typical layer structure and generated three sharp, symmetric characteristic peaks that can be assigned to the reflections of the (002), (004) and (020) planes. The peak intensities of the samples are different due to variations in the valances and dimensions of the ions. The Mg-CAP shows excellent crystallinity compared with the CAP sample, suggesting that $\mathrm{Mg}^{2+}$ favors the formation of the LDH structure. However, the peak intensities of the other M-CAP samples are lower than those of the CAP, demonstrating comparatively poor crystallinity.

Following calcination, all samples were in the form of composite oxides (Fig. 1(b)). A mayenite $\left(\mathrm{Ca}_{12} \mathrm{Al}_{14} \mathrm{O}_{33}\right)$ phase is observed in the pattern of each sample, indicating an interaction between $\mathrm{Ca}$ and $\mathrm{Al}$. In the case of the Mg-CA, the intensity of the $\mathrm{CaO}$ peak is much higher than those of the other met- al-modified samples. Moreover, the chemical interaction between $\mathrm{Mg}$ and $\mathrm{Al}$ evidently generated a new $\mathrm{MgAl}_{2} \mathrm{O}_{4}$ phase. It is also apparent that La interacted with $\mathrm{Ca}$ and $\mathrm{Al}$ to form a $\mathrm{CaLaAlO}_{4}$ phase, while $\mathrm{Y}$ only interacted with $\mathrm{Al}$ to form an $\mathrm{Al}_{5} \mathrm{Y}_{3} \mathrm{O}_{12}$ phase. Interestingly, the Ce-CA sample demonstrates a $\mathrm{CeO}_{2}$ phase with a weak $\mathrm{Ca}_{12} \mathrm{Al}_{14} \mathrm{O}_{33}$ peak, possibly because the introduction of Ce leads to a disordered structure.

\subsection{TG analysis}

The TGA-DTG data acquired from the CAP and M-CAP samples are depicted in Fig. 2, and indicate the typical thermal decomposition stages of LDH structures [36]. In the case of the CAP sample, three major mass losses are observed [36]. The first occurs over the range of 300-426 K and corresponds to the removal of physically absorbed and interlayer water. The second mass loss in the range of 548-583 K can be attributed to the de-hydroxylation of the inorganic layers, leading to collapse of the layered structure, while the final mass loss at 871-983 K can be ascribed to the decomposition of the subject-object structure. However, it is clear that the M-CAP samples behave differently. The decomposition of these materials occurs at lower temperatures, especially that of the Ce-CAP, suggesting that the insertion of metal ions may distort the main structure and decrease the thermal stability of Ca-Al LDHs.

\subsection{IR analysis}

FT-IR spectroscopy was employed to study the structural features of CAP and CA samples (Fig. 3). The $\mathrm{O}-\mathrm{H}$ stretching vibration of free water at $3644 \mathrm{~cm}^{-1}$ can be observed [12] in these spectra, and the stretching mode of hydroxyl groups in layer and interlayer water molecules appears as a broad band at approximately $3455 \mathrm{~cm}^{-1}$ [37]. The band at $1621 \mathrm{~cm}^{-1}$ is due to the bending vibration of physically absorbed water [38]. The band at $1400 \mathrm{~cm}^{-1}$ demonstrates the presence of mono and
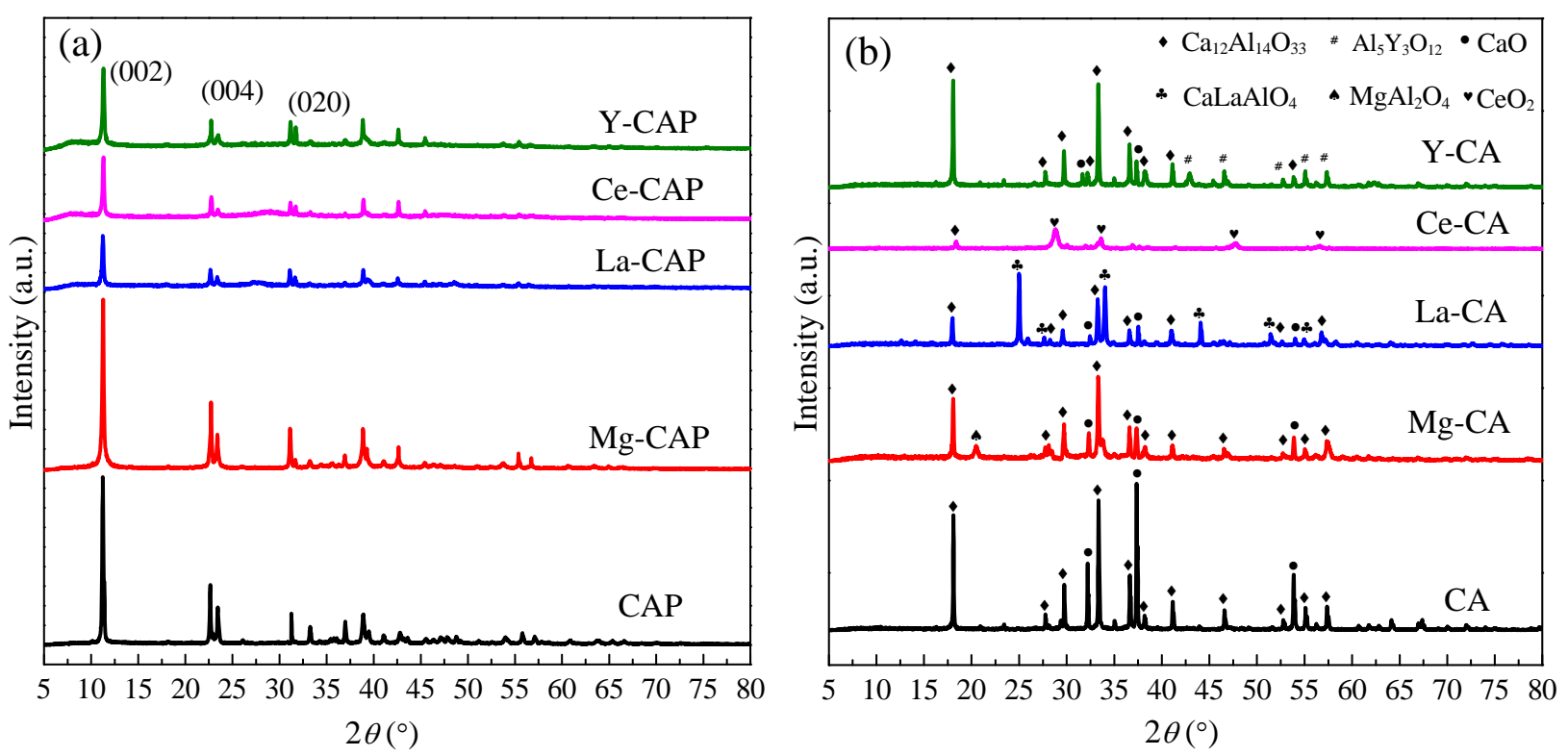

Fig. 1. The XRD patterns of CAP and M-CAP (a) and CA and M-CA (b) samples. 

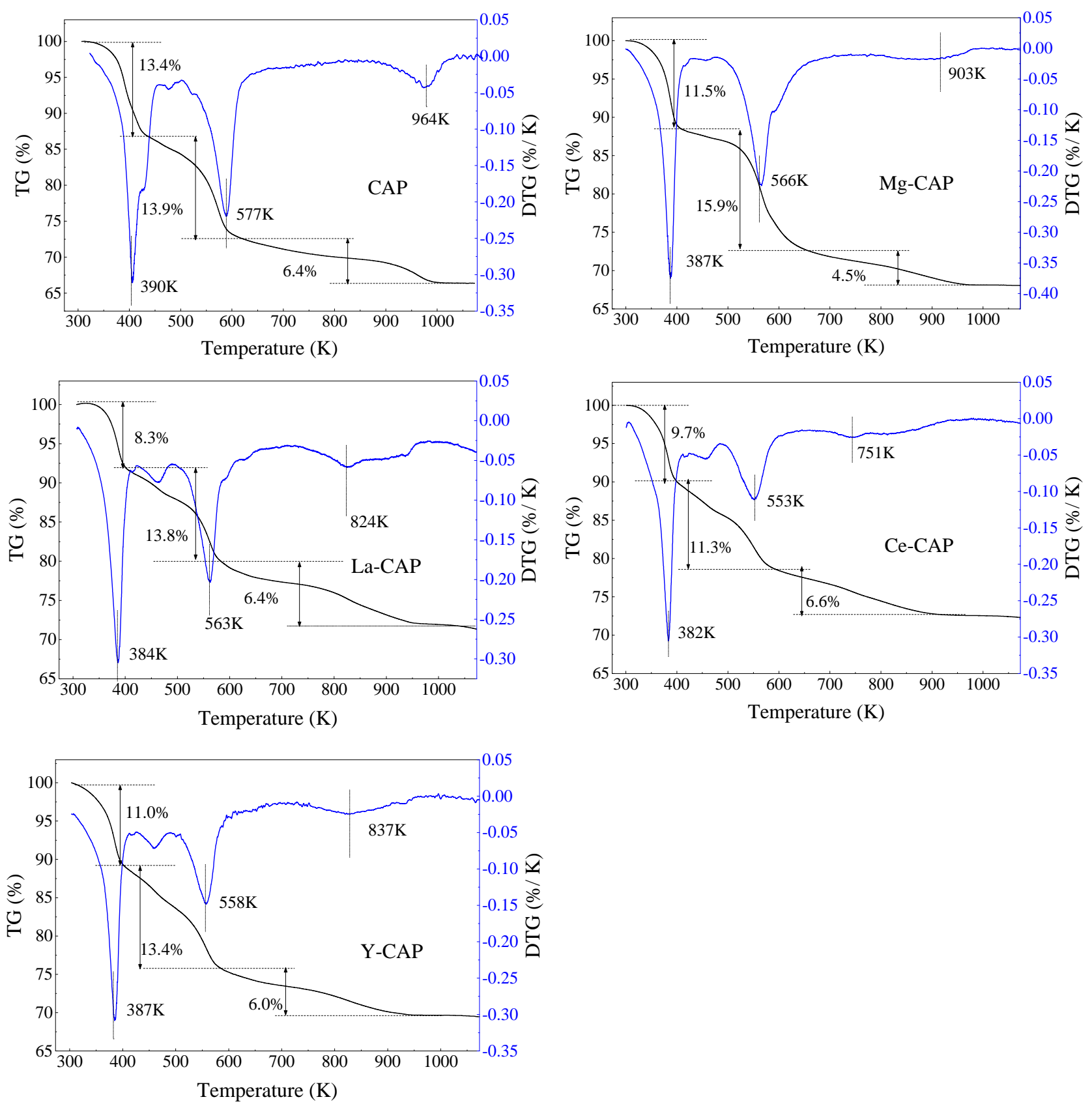

Fig. 2. TGA-DTG profiles of the CAP and M-CAP samples.

bidentate carbonates, even though carbonates were not detected by XRD, confirming that the catalyst surfaces were subjected to a high degree of carbonation [39,40]. In addition, bands attributed to metal- $\mathrm{OH}$ bonds are also evident at 782 , 526 and $427 \mathrm{~cm}^{-1}$.

After calcination at $1073 \mathrm{~K}$, all samples show considerable changes. A broad but less intense band appears at $3460 \mathrm{~cm}^{-1}$ and can be assigned to the stretching mode of hydroxyl groups. Weak bands originating from surface carbonate or hydrogen carbonate species are also present as a result of the adsorption of atmospheric $\mathrm{CO}_{2}$ on the external surfaces of the catalysts during handling. The band at $1410 \mathrm{~cm}^{-1} \mathrm{can}$ be ascribed to the $\mathrm{O}-\mathrm{C}-\mathrm{O}$ stretching vibrations of adsorbed carbonate anions on the surface basic sites of the catalysts. The intensity of this peak in the Mg-CA and La-CA spectra is higher than in the case of the pure CA sample, suggesting a greater carbonate content on the surfaces of the former materials than on the pure CA, because of higher surface basicity. Therefore, introducing the appropriate amounts of Mg or La may increase the surface basicity of these materials [41]. In the low wavenumber region (400-1000 $\left.\mathrm{cm}^{-1}\right)$, the bands related to metal- $\mathrm{OH}$ bonds shift to higher wavenumbers. It is also apparent that the spectra are dominated by a strong band at $852 \mathrm{~cm}^{-1}$ (attributed to metal-oxygen bonds) that is absent in the patterns obtained from the CAP and M-CAP samples, suggesting that metal oxides are formed during calcination. Variations in the shapes and intensities of these bands between specimens may originate from the formation of different oxide species. 

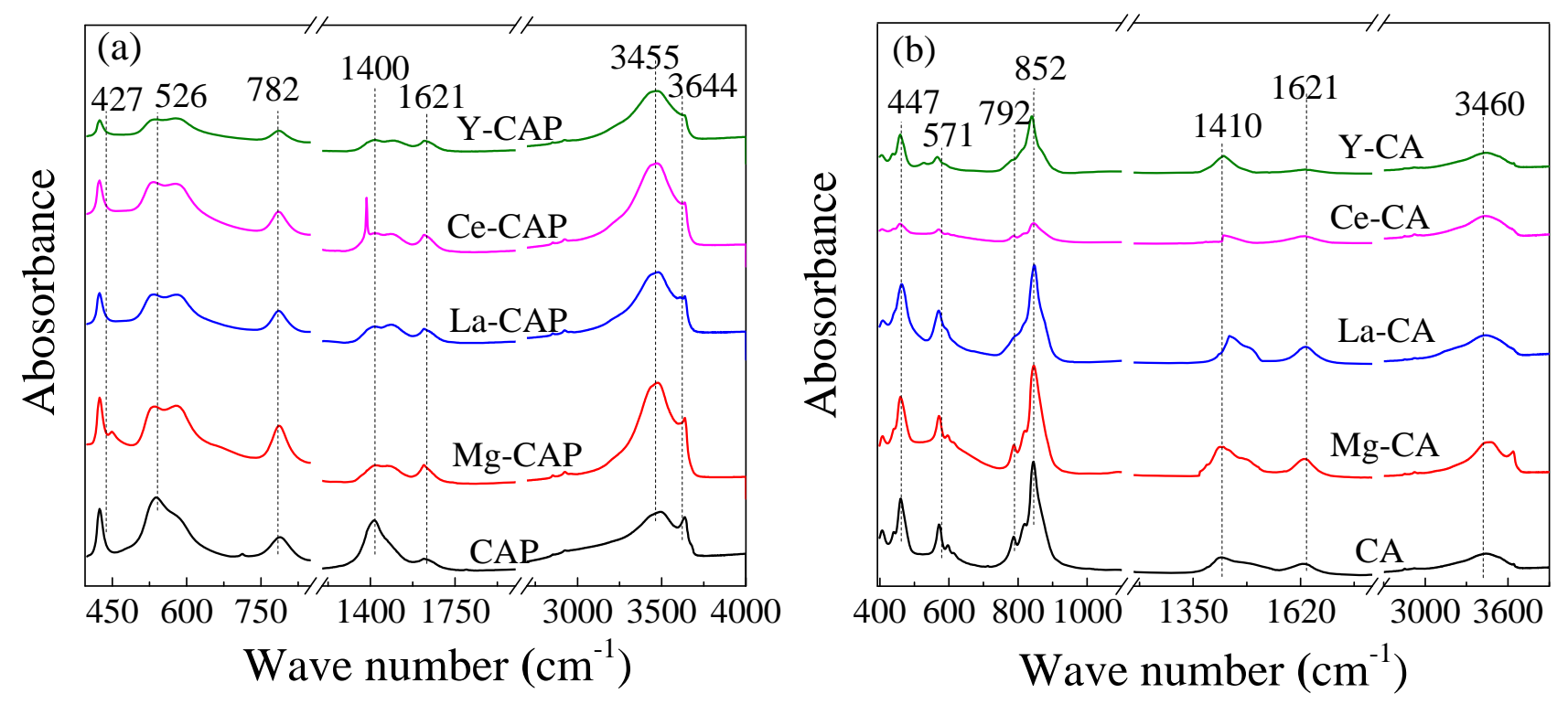

Fig. 3. FT-IR spectra of CAP and M-CAP (a) and CA and M-CA (b) samples.

\subsection{XPS and ICP analyses}

The surface properties and compositions of the CA and M-CA catalysts were assessed by XPS, and the data in Table 1 show that the $\mathrm{Ca}$ and $\mathrm{Al} \mathrm{BE}$ values are very similar for all samples. Fig. 4 provides the XPS spectra of the CA and M-CA catalysts. The Mg-CA Mg $2 p$ spectrum contains a single peak at 50.0 $\mathrm{eV}$ that is consistent with the presence of $\mathrm{Mg}^{2+}$ [42]. In addition, the La $3 d_{5 / 2}$ core-level peak is located at a BE of $834.8 \mathrm{eV}$, a value that is higher than those reported for $\mathrm{La}_{2} \mathrm{O}_{3}(834.3 \mathrm{eV})$ [43] or $\mathrm{LaAlO}_{3}(833.8 \mathrm{eV}$ ) [44]. This peak can therefore be assigned to well-dispersed La species [45]. In the Ce $3 d$ spectrum, the three main Ce $3 d_{5 / 2}$ features at $882.1,888.1$ and $897.8 \mathrm{eV}$ and the three main $\mathrm{Ce} 3 d_{3 / 2}$ features at $900.3,907.0$ and 916.2 $\mathrm{eV}$ can be ascribed to $\mathrm{Ce}^{4+}$ in $\mathrm{CeO}_{2}$ [46], which is consistent with the XRD results. Two other peaks, at 883.6 and $901.3 \mathrm{eV}$, are also evident and are attributed to $\mathrm{Ce}^{3+}$. In the case of the Y-CA catalyst, four peaks are present at 156.4, 157.7, 158.4 and 160.1 $\mathrm{eV}$, corresponding to $\mathrm{Y} 3 d_{5 / 2}$ and $\mathrm{Y} 3 d_{3 / 2}$ electrons $[47,48]$. Compared with the peaks generated by pure $\mathrm{Y}_{2} \mathrm{O}_{3}$ at approximately 156.8 and $158.9 \mathrm{eV}$ [49], the higher Y $3 d \mathrm{BE}$ values (157.7 and $160.1 \mathrm{eV}$ ) suggest that the $\mathrm{Y}$ atoms have combined with atmospheric moisture to produce $\mathrm{Y}-\mathrm{OH}$ or $\mathrm{Y}-\mathrm{OC}$ sites [48]. The 0 is spectra of the CA and M-CA catalysts contain three intense peaks at 530, 531 and $532 \mathrm{eV}$, ascribed to lattice

Table 1

The binding energy values of the CA and M-CA catalysts.

\begin{tabular}{lccc}
\hline \multirow{2}{*}{ Catalyst } & \multicolumn{3}{c}{ Binding energy $(\mathrm{eV})$} \\
\cline { 2 - 4 } & Ca $2 p$ & $\mathrm{Al} 2 p$ & $01 s$ \\
\hline CA & $350.7 ; 347.2$ & 74.2 & $530.5 ; 531.4 ; 532.3$ \\
Mg-CA & $350.7 ; 347.1$ & 74.2 & $530.1 ; 530.9 ; 532.1$ \\
La-CA & $350.7 ; 347.1$ & 73.9 & $530.1 ; 531.1 ; 532.1$ \\
Ce-CA & $350.6 ; 347.1$ & 73.9 & $530.4 ; 531.3 ; 532.2$ \\
Y-CA & $350.6 ; 347.0$ & 73.8 & $530.6 ; 531.5 ; 532.4$ \\
\hline
\end{tabular}

$\mathrm{O}^{2}$, surface hydroxyl groups and carbonate groups, respectively [50,51]. It can be seen that the $01 s$ BEs of the catalysts modified with Mg, La or Ce are shifted to lower values (Table 1), and so the electron pair donating ability of the surface oxygen atoms may be enhanced [52,53].

The textural parameters and metal compositions of the catalysts are summarized in Table 2. Compared with the CA catalyst, the specific surface areas and pore volumes of the catalysts were increased with the introduction of $\mathrm{Mg}$, La or Ce. In addition, the surface concentrations of the metals and of Ca are noticeably higher, suggesting that the catalyst surfaces were enriched in these elements. Notably, the Mg-CA and La-CA catalysts exhibit lower Al levels compared with the other catalysts.

\subsection{Basicity analyses}

The basicity of each catalyst was determined using $\mathrm{CO}_{2}$-TPD and Hammett indicators. The $\mathrm{CO}_{2}$-TPD profiles of the $\mathrm{CA}$ and M-CA catalysts are shown in Fig. 5. For all catalysts, the broad peak ranging from 300 to $700 \mathrm{~K}$ can be divided into two peaks (peak $\alpha$ and peak $\beta$ ), attributed to weak and moderate basic sites that primarily result from basic $\mathrm{OH}^{-}$groups and $\mathrm{M}^{\mathrm{x}+} \mathrm{O}^{2-}$ pairs. Another broad peak (peak $\gamma$ ) between 700 and $900 \mathrm{~K}$ can be ascribed to strongly basic sites associated with unsaturated $\mathrm{O}^{2^{-}}$anions. The CA catalyst shows a symmetric desorption peak at $800 \mathrm{~K}$, whereas the M-CA generates more complex data in which more than two Gaussian peaks are present, suggesting that the addition of metal ions has a significant effect on the strongly basic surface sites. Prior studies have demonstrated that the peaks above $900 \mathrm{~K}$ can be assigned to super strong basic sites [54]. The $\mathrm{CO}_{2}$-TPD profiles confirm that super strong basic site (peak $\delta$ ) were present on the Mg-CA and La-CA catalysts. Therefore, the introduction of Mg and La evidently generates a certain number of super strong basic sites, possibly due to the rearrangement of isolated $\mathrm{O}^{2-}$ ions on the catalyst surfaces. Wu et al. [55] reported that the $\mathrm{M}^{\mathrm{x}-}-\mathrm{O}^{2-}$ pairs on the cat- 

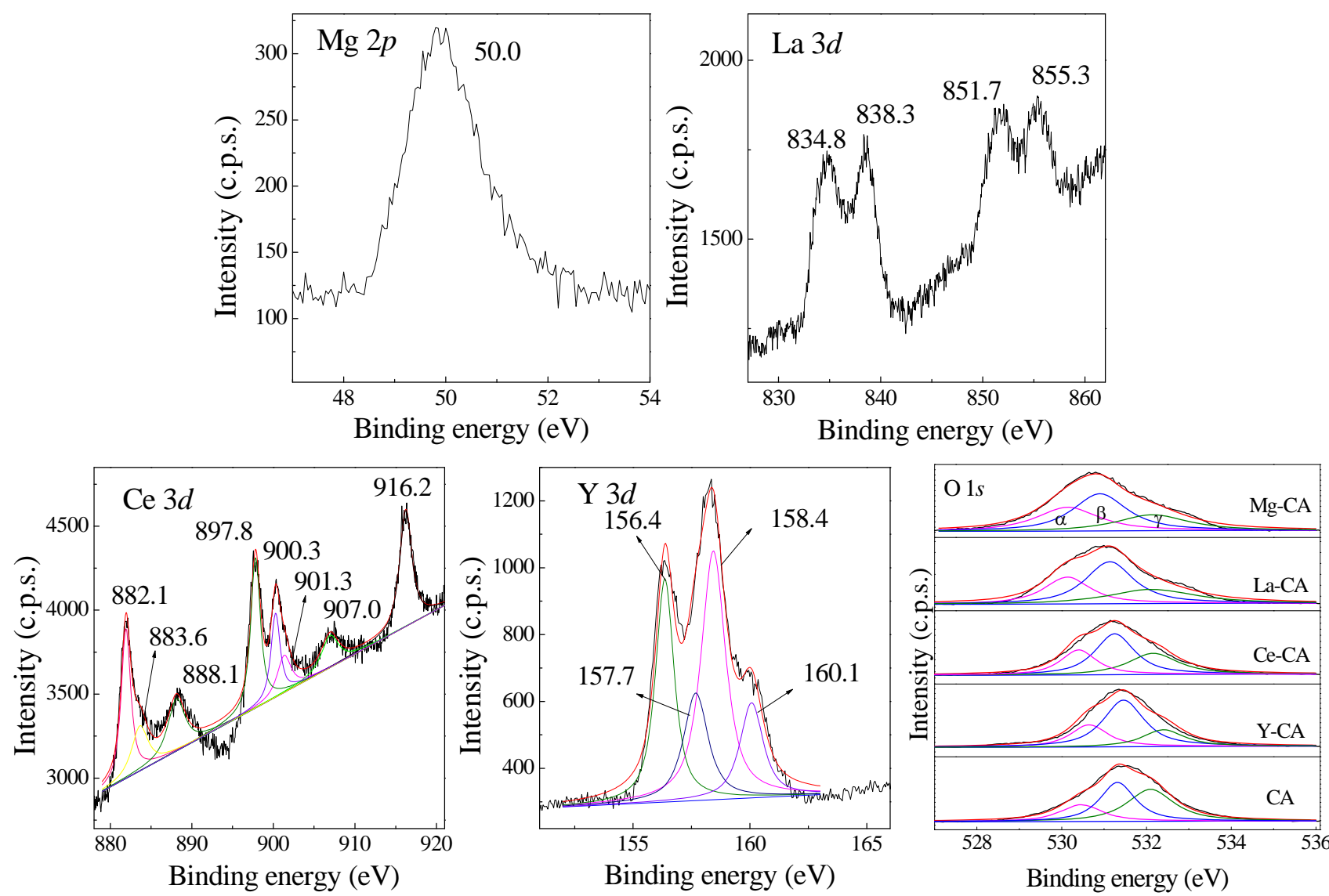

Fig. 4. XPS spectra of CA and M-CA catalysts.

alyst surface could partially split to generate unsaturated $\mathrm{O}^{2-}$ ions. The Mg-CA catalyst was found to have the highest $(\mathrm{Mg}+\mathrm{Ca})$ :Al atomic ratio among the catalysts (Table 2), which may be responsible for the presence of more unsaturated $\mathrm{O}^{2-}$ ions, leading to the highest concentration of super strong basic sites.

The base strength $\left(H_{-}\right)$of each catalyst was subsequently assessed using Hammett indicators. The basicity distributions of the catalysts are summarized in Table 3 . According to the results of titrations, three basic sites were identified: weak (9.3-15.0), medium (15.0-18.4) and strong (18.4-26.5). Noticeably, values in the super strong basic strength range (26.5-35.0) were found with the introduction of $\mathrm{Mg}$ and $\mathrm{La}$, which is consistent with the $\mathrm{CO}_{2}$-TPD results.

The total basic amounts determined from the Hammett indicators were relatively high compared with those obtained from $\mathrm{CO}_{2}$-TPD, because $\mathrm{CO}_{2}$-TPD primarily responds to surface basic sites, while titrations with Hammett indicators can detect both exposed and internal basic sites. The total amounts of basic sites determined by both methods were in the same order of $\mathrm{Y}$-CA $<$ CA $<$ Ce-CA $<$ La-CA $<$ Mg-CA.

\subsection{Catalytic performance}

The effects of the methanol/PC molar ratio and catalyst mass on DMC yields were investigated (Fig. 6). The data demonstrate that the yield increases along with the methanol/PC molar ratio within a certain range and then falls somewhat at a ratio of 15 because the PC concentration becomes too low for the transesterification to proceed efficiently [56]. In contrast, the yield only exhibits a slight increased up to a catalyst mass of $2 \mathrm{wt} \%$ with minimal changes above that level, suggesting that reaction equilibrium has been reached [57]. Therefore, the optimum reaction conditions consist of a meth-

Table 2

The textural parameters and metal compositions of the CA and M-CA catalysts.

\begin{tabular}{|c|c|c|c|c|c|c|}
\hline \multirow{2}{*}{ Catalyst } & \multirow{2}{*}{$\begin{array}{c}S_{\text {BET }} \\
\left(\mathrm{m}^{2} / \mathrm{g}\right)\end{array}$} & \multirow{2}{*}{$\begin{array}{c}V_{\text {pore }} \\
\left(\mathrm{cm}^{3} / \mathrm{g}\right)\end{array}$} & \multicolumn{3}{|c|}{ Relative concentration of metal a (at\%) } & \multirow{2}{*}{$\begin{array}{c}\text { Atomic ratio }^{a} \\
(\mathrm{M}+\mathrm{Ca}): \mathrm{Al}\end{array}$} \\
\hline & & & $\mathrm{M}$ & $\mathrm{Ca}$ & $\mathrm{Al}$ & \\
\hline $\mathrm{CA}$ & 37.6 & 0.26 & 0 & $62.7(60.4)$ & $37.3(39.6)$ & $1.68(1.53)$ \\
\hline Mg-CA & 42.3 & 0.30 & $17.0(15.9)$ & $48.9(46.2)$ & $34.1(37.9)$ & $1.93(1.64)$ \\
\hline La-CA & 41.1 & 0.29 & $18.1(16.3)$ & $46.8(45.7)$ & $35.1(38.0)$ & $1.85(1.63)$ \\
\hline Ce-CA & 40.1 & 0.27 & $21.4(16.6)$ & $43.0(41.6)$ & $35.6(41.8)$ & $1.81(1.39)$ \\
\hline Y-CA & 36.7 & 0.23 & $23.1(16.8)$ & $41.2(40.9)$ & $35.7(42.3)$ & $1.80(1.36)$ \\
\hline
\end{tabular}

a The values outside and inside the parentheses were obtained by XPS and ICP measurements, respectively. 


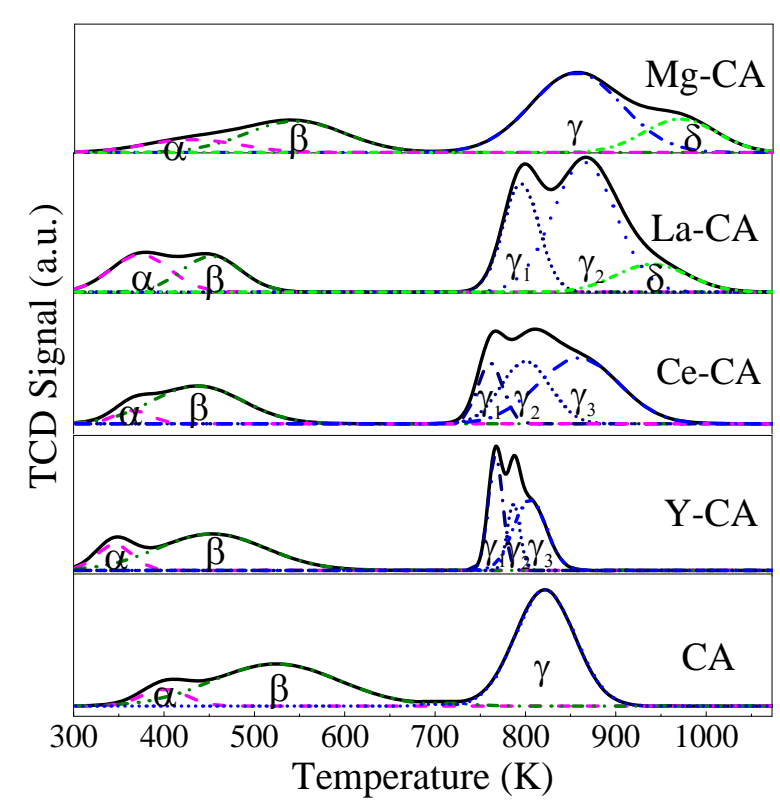

Fig. 5. $\mathrm{CO}_{2}$-TPD profiles of the $\mathrm{CA}$ and M-CA catalysts.

anol/PC molar ratio of 12 and a catalyst mass of $2 \mathrm{wt} \%$. The catalytic activity increases in the order of $\mathrm{Y}-\mathrm{CA}<\mathrm{CA}<\mathrm{Ce}-\mathrm{CA}<$ La-CA $<$ Mg-CA, and the highest PC conversion of 55.3\% and DMC selectivity of $96.3 \%$ were obtained over the Mg-CA catalyst (Table 4).

During the reaction, the role of the basic sites is to activate $\mathrm{CH}_{3} \mathrm{OH}$ to form $\mathrm{CH}_{3} \mathrm{O}^{-}$, which then attacks $\mathrm{PC}$ to produce DMC. Many studies $[10,58,59]$ have reported that catalysts having the highest basic amounts will exhibit the best catalytic performance, and that high basic strength is also responsible for promoting the reaction [59]. In this study, the introduction of $\mathrm{Mg}$, La or Ce increased the total surface basic amount of the catalysts. This is also reflected by increases in the DMC yields. The activity of the catalysts increases in the order of $\mathrm{Y}-\mathrm{CA}<\mathrm{CA}$ $<$ Ce-CA $<$ La-CA $<$ Mg-CA, which is in good agreement with the basicity of the catalysts as calculated using the $\mathrm{CO}_{2}$-TPD results. Thus, the relationship between the surface basicity and DMC yield was investigated. Fig. 7 demonstrates that the total surface basic amount and density of the as-prepared catalyst both have a linear relationship with the DMC yield.

\subsection{Recyclability tests}

Fig. 8 presents the results of recyclability trials using the catalysts. Although the initial activity of the CA-mixing catalyst
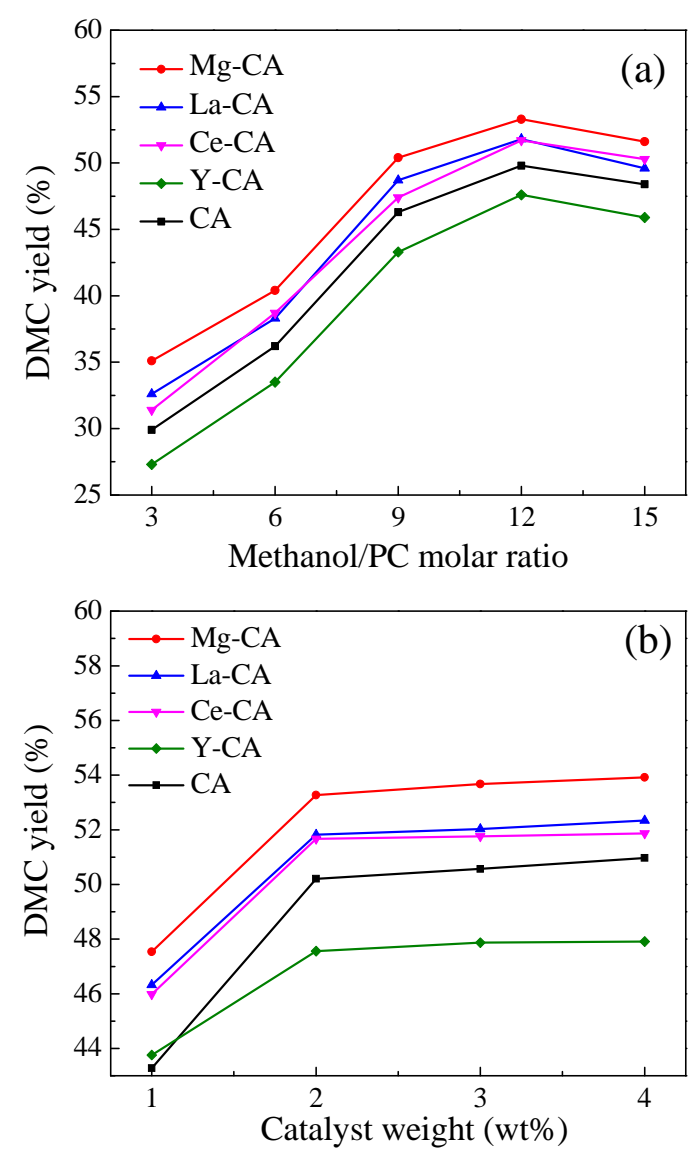

Fig. 6. Catalytic performance of the CA (a) and M-CA (b) catalysts.

\section{Table 4}

Catalytic performances and basicity values of the CA and M-CA catalysts.

\begin{tabular}{lccccc}
\hline Catalyst & $\begin{array}{c}\text { PC } \\
\text { conversion } \\
(\%)\end{array}$ & $\begin{array}{c}\text { DMC } \\
\text { selectivity } \\
(\%)\end{array}$ & $\begin{array}{c}\text { DMC } \\
\text { yield } \\
(\%)\end{array}$ & $\begin{array}{c}\text { Total basic } \\
\text { amount }^{\text {a }} \\
(\mathrm{mmol} / \mathrm{g})\end{array}$ & $\begin{array}{c}\text { Total basic } \\
\text { density a } \\
\left(\mu \mathrm{mol} / \mathrm{m}^{2}\right)\end{array}$ \\
\hline Mg-CA & 55.3 & 96.3 & 53.3 & 1.05 & 24.82 \\
La-CA & 54.1 & 95.7 & 51.8 & 0.97 & 23.60 \\
Ce-CA & 54.3 & 95.1 & 51.7 & 0.94 & 23.44 \\
Y-CA & 52.4 & 90.9 & 47.6 & 0.74 & 20.16 \\
CA & 53.7 & 92.8 & 49.8 & 0.80 & 21.28 \\
\hline
\end{tabular}

Reaction conditions: methanol/PC molar ratio $=12$, catalyst mass $=2$ wt $\%$ of total reactants, $333 \mathrm{~K}, 2 \mathrm{~h}$.

a Determined by $\mathrm{CO}_{2}$-TPD.

is the highest, the activity deceases drastically after the tenth recycling. This effect may have resulted from the weak interaction between $\mathrm{Ca}$ and $\mathrm{Al}$ in the CA-mixing sample. In the case of

Table 3

The basicity distributions and basic amounts of the CA and M-CA catalysts.

\begin{tabular}{|c|c|c|c|c|c|c|c|c|c|c|}
\hline \multirow{2}{*}{ Catalyst } & \multicolumn{4}{|c|}{$\mathrm{CO}_{2}$ uptake ${ }^{\mathrm{a}}(\mathrm{mmol} / \mathrm{g})$} & \multirow{2}{*}{$\begin{array}{l}\text { Total basic amount a } \\
\text { (mmol/g) }\end{array}$} & \multicolumn{4}{|c|}{ Base strength $H_{-}$distribution ${ }^{\mathrm{b}}(\mathrm{mmol} / \mathrm{g})$} & \multirow{2}{*}{$\begin{array}{c}\text { Total basic amount } \mathrm{b} \\
(\mathrm{mmol} / \mathrm{g})\end{array}$} \\
\hline & $\alpha$ & $\beta$ & $\gamma$ & $\delta$ & & $9.3-15.0$ & $15.0-18.4$ & $18.4-26.5$ & $26.5-35.0$ & \\
\hline $\mathrm{Mg}-\mathrm{CA}$ & 0.09 & 0.23 & 0.54 & 0.19 & 1.05 & 0.12 & 0.25 & 0.60 & 0.22 & 1.19 \\
\hline La-CA & 0.10 & 0.11 & 0.64 & 0.12 & 0.97 & 0.14 & 0.19 & 0.69 & 0.15 & 1.17 \\
\hline Ce-CA & 0.03 & 0.23 & 0.68 & 0 & 0.94 & 0.07 & 0.29 & 0.76 & 0 & 1.12 \\
\hline Y-CA & 0.06 & 0.31 & 0.37 & 0 & 0.74 & 0.11 & 0.33 & 0.42 & 0 & 0.86 \\
\hline CA & 0.10 & 0.26 & 0.44 & 0 & 0.80 & 0.10 & 0.39 & 0.54 & 0 & 1.03 \\
\hline
\end{tabular}

a Determined by $\mathrm{CO}_{2}$-TPD.

b Determined from Hammett indicators. 

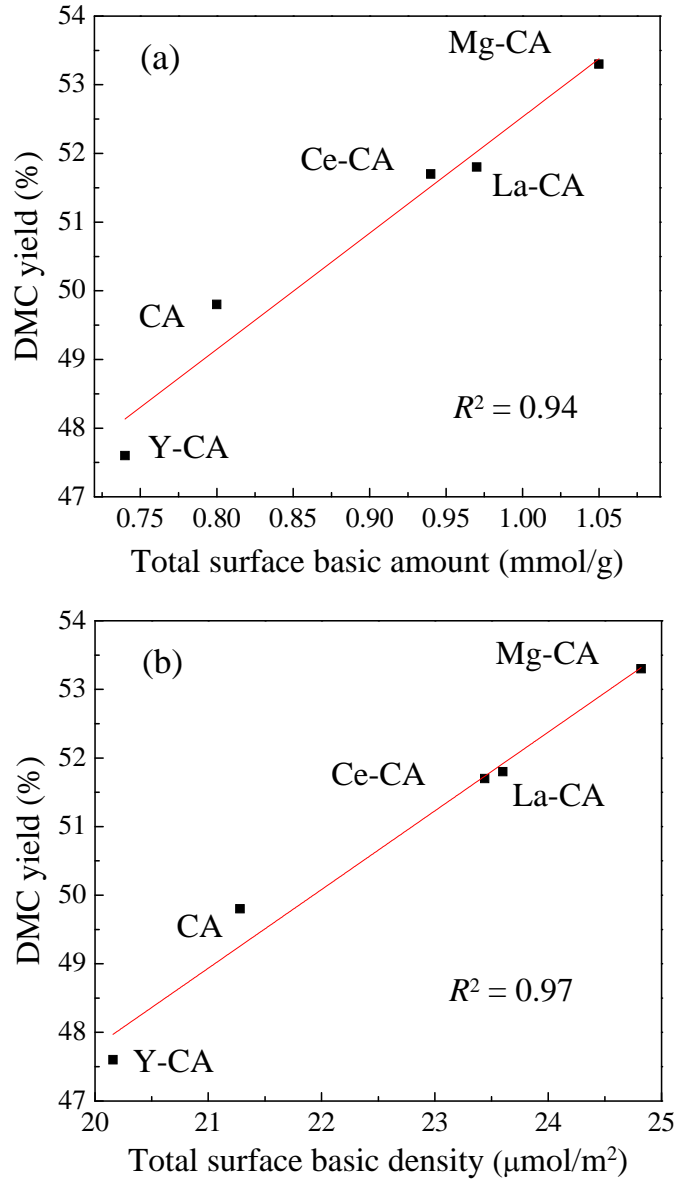

Fig. 7. The relationship between the DMC yield and the total surface basic amount (a) and basic density (b). Reaction conditions: methanol $/ \mathrm{PC}$ molar ratio $=12$, catalyst mass $=2 \mathrm{wt} \%$ of total reactants, $333 \mathrm{~K}$, $2 \mathrm{~h}$.

the CA catalyst, the DMC yield decreases by $12.6 \%$ after 10 recycling runs, suggesting that the recyclability of this materials has been improved owing to the increased interaction between $\mathrm{Ca}$ and Al. Following modification with metal ions, the M-CA catalysts exhibit a longer recycle life compared with the

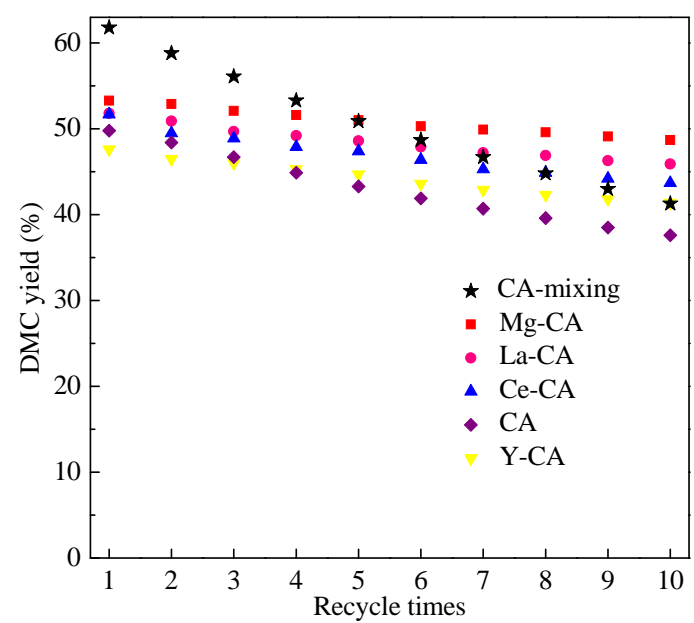

Fig. 8. Results of recyclability trials using the CA-mixing, CA and M-CA catalysts. Reaction conditions: methanol/PC molar ratio $=12$, catalyst mass $=2 \mathrm{wt} \%$ of total reactants, $333 \mathrm{~K}, 2 \mathrm{~h}$.

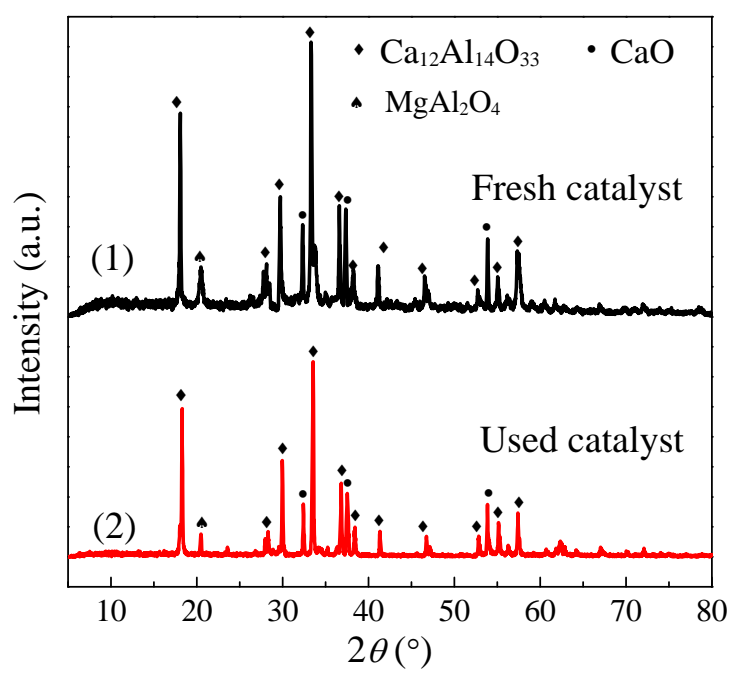

Fig. 9. XRD patterns of fresh (1) and used (2) Mg-CA catalyst samples.

Table 5

Catalytic performances and metal compositions of fresh and used Mg-CA catalyst samples.

\begin{tabular}{lccccc}
\hline \multirow{2}{*}{ Catalyst } & PC & DMC & \multicolumn{3}{c}{$\begin{array}{c}\text { Relative concentration } \\
\text { of metal a (at\%) }\end{array}$} \\
\hline Fresh Mg-CA catalyst & 55.3 & 96.3 & 15.9 & 46.2 & 37.9 \\
\cline { 4 - 6 } 10 times recycled & 52.6 & 92.5 & 15.0 & 44.9 & 40.1 \\
\hline
\end{tabular}

Reaction conditions: methanol/PC molar ratio $=12$, catalyst mass $=2$ wt $\%$ of total reactants, $333 \mathrm{~K}, 2 \mathrm{~h}$. ${ }^{\text {a Determined by ICP. }}$

CA-mixing and CA catalysts, such that the catalytic performance of the former is higher than those of the latter after five recycling runs. Finally, the recyclability of the catalysts after 10 recycling runs increases in the order of CA-mixing $<\mathrm{CA}<\mathrm{Ce}-\mathrm{CA}$ $<\mathrm{Y}$-CA $<$ La-CA $<$ Mg-CA. This excellent recyclability may be ascribed to the intermetallic interactions induced by the addition of metals, which stabilize the active species of the catalysts.

The XRD patterns of the fresh and ten times recycled Mg-CA catalyst are provided in Fig. 9. It is evident that there is no difference in the patterns after ten recycling trials, suggesting significant stability. The chemical compositions of the fresh and recycled samples are also summarized in Table 5. The decrease in the catalytic performance after 10 recycling runs can be ascribed to a slight loss of active Ca and Mg ions.

\section{Conclusions}

LDHs containing various alkaline earth or rare earth metals Ca-M-Al (M = Mg, La, Ce, Y) were prepared and applied to a transesterification reaction after calcination. XRD analysis results indicate that Ca-M-Al LDHs were successfully synthesized and subsequently decomposed to give the corresponding metal oxides during calcination. The surfaces of these catalysts were rich in $\mathrm{Mg}$, La, Ce or $\mathrm{Y}$ as well as in Ca, as demonstrated by XPS data. The results from basicity analyses by $\mathrm{CO}_{2}$-TPD and Hammett titrations show that the basicity of the catalysts is increased following modification with $\mathrm{Mg}$, La or Ce. The total surface basic amount and density both exhibited a linear cor- 
relation with the DMC yield. Furthermore, the recyclability of the M-CA catalysts was improved, such that a Ca-Mg-Al specimen maintained the highest activity after 10 recycling trials, with no appreciable variations in its XRD pattern with repeated use. The work reported herein is expected to lead to the development of high-efficiency solid base catalysts for the transesterification of PC with methanol. Such catalysts offer a simple, ecologically safe, cost effective and energy efficient means of synthesizing DMC while also allowing facile recycling.

\section{References}

[1] Y. Ono, Appl. Catal. A, 1997, 155, 133-166.

[2] D. F. Wang, X. L. Zhang, J. Ma, H. W. Yu, J. Z. Shen, W. Wei, Catal. Sci. Technol., 2016, 6, 1530-1545.

[3] D. D. Wu, Z. Chen, Ind. Eng. Chem. Res., 2009, 48, 6287-6290.

[4] S. Y. Huang, B. Yan, S. P. Wang, X. B. Ma, Chem. Soc. Rev., 2015, 44, 3079-3116.

[5] G. Merza, B. László, A. Oszkó, G. Pótári, E. Varga, A. Erdőhelyi, Catal. Lett., 2014, 145, 881-892.

[6] R. G. Zhang, J. R. Li, B. J. Wang, RSC Adv., 2013, 3, 12287-12298.

[7] J. Q. Wang, J. Sun, W. G. Cheng, C. Y. Shi, K. Dong, X. P. Zhang, S. J. Zhang, Catal. Sci. Technol., 2012, 2, 600-605.

[8] A. Pyrlik, W. F. Hoelderich, K. Müller, W. Arlt, J. Strautmann, D. Kruse, Appl. Catal. B, 2012, 125, 486-491.

[9] H. Wang, M. H. Wang, S. G. Liu, N. Zhao, W. Wei, Y. H. Sun, J. Mol. Catal. A, 2006, 258, 308-312.

[10] P. Kumar, V. C. Srivastava, I. M. Mishra, Energy Fuels, 2015, 29, 2664-2675.

[11] C. C. Wu, X. Q. Zhao, Y. J. Wang, Catal. Commun., 2005, 6, 694-698.

[12] X. M. Wu, M. Kang, N. Zhao, W. Wei, Y. H. Sun, Catal. Commun., 2014, 46, 46-50.

[13] C. Zhang, B. Lu, X. G. Wang, J. X. Zhao, Q. H. Cai, Catal. Sci. Technol., 2012, 2, 305-309.

[14] J. Bian, M. Xiao, S. J. Wang, X. J. Wang, Y. X. Lu, Y. Z. Meng, Chem. Eng.J., 2009, 147, 287-296.
[15] A. Bansode, A. Urakawa, ACS Catal., 2014, 4, 3877-3880.

[16] X. L. Wu, Y. Z. Meng, M. Xiao, Y. X. Lu, J. Mol. Catal. A, 2006, 249, 93-97.

[17] R. Srivastava, D. Srinivas, P. Ratnasamy, J. Catal., 2006, 241, 34-44.

[18] J. Xu, H. T. Wu, C. M. Ma, B. Xue, Y. X. Li, Y. Cao, Appl. Catal. A, 2013, 464-465, 357-363.

[19] C. Murugan, H. C. Bajaj, R. V. Jasra, Catal. Lett., 2010, 137, 224-231.

[20] R. Juárez, A. Corma, H. García, Green Chem., 2009, 11, 949-952.

[21] P. Kumar, V. C. Srivastava, I. M. Mishra, Catal. Commun., 2015, 60, 27-31.

[22] H. Wang, M. H. Wang, N. Zhao, W. Wei, Y. H. Sun, Catal. Lett., 2005, 105, 253-257.

[23] K. Yan, A. C. Chen, Fuel, 2014, 115, 101-108.

[24] T. Wei, M. H. Wang, W. Wei, Y. H. Sun, B. Zhong, Green Chem., 2003, 5, 343-346.

[25] K. Yan, G. S. Wu, W. Jin, Energy Technol., 2016, 4, 354-368.

[26] K. Yan, Y. Q. Liu, Y. R. Lu, J. J. Chai, L. P. Sun, Catal. Sci. Technol., 2017, 7, 1622-1645.

[27] K. Takehira, Appl. Clay Sci., 2017, 136, 112-141.

[28] H. S. Ji, W. H. Wu, F. H. Li, X. X. Yu, J. J. Fu, L. Y. Jia, J. Hazard. Mater., 2017, 334, 212-222.

[29] N. B. Allou, P. Saikia, A. Borah, R. L. Goswamee, Colloid Polym. Sci., 2017, 295, 725-747.

[30] Y. Lu, B. Jiang, L. Fang, F. L. Ling, F. Wu, B. S. Hu, F. M. Meng, K. Y. Niu, F. Lin, H. M. Zheng, J. Alloys Compd., 2017, 714, 63-70.

[31] L. P. Zheng, S. X. Xia, X. Y. Lu, Z. Y. Hou, Chin. J. Catal., 2015, 36, 1759-1765.

[32] L. P. Zheng, S. X. Xia, Z. T. Hou, M. Y. Zhang, Z. Y. Hou, Chin. J. Catal., 2014, 35, 310-318.

[33] L. J. Gao, G. Y. Teng, J. H. Lv, G. M. Xiao, Energy Fuels, 2010, 24, 646-651.

[34] C. S. Castro, L. C. F. Garcia, J. M. Assaf, Fuel Process. Technol., 2014, $125,73-78$.

[35] Z. Wang, P. Fongarland, G. Z. Lu, N. Essayem, J. Catal., 2014, 318, 108-118.

[36] J. Kocík, M. Hájek, I. Troppová, Fuel Process. Technol., 2015, 134, 297-302.

[37] F. Cavani, F. Trifirb, A. Vaccari, Catal. Today, 1991, 11, 173-301.

\section{Graphical Abstract}

Chin. J. Catal., 2017, 38: 1860-1869 doi: 10.1016/S1872-2067(17)62898-5

Solid base catalysts derived from Ca-M-Al ( $\mathrm{M}=\mathrm{Mg}, \mathrm{La}, \mathrm{Ce}, \mathrm{Y}$ ) layered double hydroxides for dimethyl carbonate synthesis by transesterification of methanol with propylene carbonate

Yunhui Liao, Feng Li *, Xin Dai, Ning Zhao, Fukui Xiao *

Institute of Coal Chemistry, Chinese Academy of Sciences; University of Chinese Academy of Sciences;

National Engineering Research Center for Coal-Based Synthesis

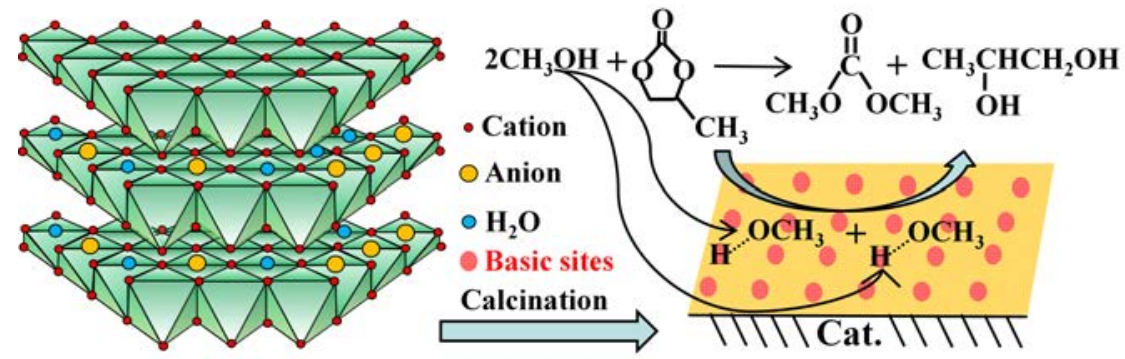

Solid base catalysts derived from Ca-M-Al (M = Mg, La, Ce, Y) layered double hydroxides were found to be both recyclable and highly active during dimethyl carbonate production under heterogeneous conditions. 
[38] F. Li, Y. F. Wang, Q. Z. Yang, D. G. Evans, C. Forano, X. Duan, J. Hazard. Mater., 2005, 125, 89-95.

[39] A. C. Vieira, R. L. Moreira, A. Dias, J. Phys. Chem. C, 2009, 113, 13358-13368.

[40] B. Yu, H. Bian, J. Plank, J. Phys. Chem. Solids, 2010, 71, 468-472.

[41] S. S. Peng, M. H. Yang, W. K. Zhang, X. N. Li, C. Wang, M. B. Yue, Microporous Mesoporous Mater., 2017, 242, 18-24.

[42] J. Li, D. Wang, G. D. Zhou, Y. X. Xue, C. Li, T. X. Cheng, Ind. Eng. Chem. Res., 2011, 50, 10955-10961.

[43] X. Chen, Y. Liu, G. Niu, Z. Yang, M. Bian, A. He, Appl. Catal. A, 2001, 205, 159-172.

[44] L. P. Haack, J. E. DeVries, K. Otto, M. S. Chattha, Appl. Catal. A, 1992, 82, 199-214.

[45] J. S. Ledford, M. Houalla, A. Proctor, D. M. Hercules, L. Petrakis, J. Chem. Phys., 1989, 93, 6770-6777.

[46] A. F. Lucrédio, G. Tremiliosi Filho, E. M. Assaf, Appl. Surf. Sci., 2009, 255, 5851-5856.

[47] T. Gougousi, Z. Y. Chen, Thin Solid Films, 2008, 516, 6197-6204.

[48] S. A. Barve, Jagannath, M. N. Deo, R. Kishore, A. Biswas, L. M. Gantayet, D. S. Patil, Appl. Surf. Sci., 2010, 257, 215-221.
[49] Y. Uwamino, T. Ishizuka, H. Yamatera, J. Electron. Spectrosc. Relat. Phenom., 1984, 34, 67-78.

[50] J. Y. Wang, L. M. Yang, W. Luo, G. X. Yang, C. L. Miao, J. Y. Fu, S. Y. Xing, P. Fan, P. M. Lv, Z. M. Wang, Fuel, 2017, 196, 306-313.

[51] L. L. Marciniuk, P. Hammer, H. O. Pastore, U. Schuchardt, D. Cardoso, Fuel, 2014, 118, 48-54.

[52] J. Campbell, Int. Mater. Rev., 1994, 39, 125-125.

[53] G. Busca, Chem. Rev., 2010, 110, 2217-2249.

[54] H. Gorzawski, W. F. Hoelderich, J. Mol. Catal. A, 1999, 144, 181-187.

[55] G. D. Wu, X. L. Wang, W. Wei, Y. H. Sun, Appl. Catal. A, 2010, 377, 107-113.

[56] P. Kumar, V. C. Srivastava, I. M. Mishra, Catal. Commun., 2015, 60, 27-31.

[57] M. K. Lam, K. T. Lee, A. R. Mohamed, Appl. Catal. B, 2009, 93, 134-139.

[58] G. D. Wu, X. L. Wang, W. Wei, Y. H. Sun, Appl. Catal. A, 2010, 377, 107-113.

[59] T. Wei, M. H. Wang, W. Wei, Y. H. Sun, B. Zhong, Fuel Process. Technol, 2003, 83, 175-182.

\title{
以Ca-M-Al (M = Mg, La, Ce, Y) 层状双氢氧化物为前驱体的固体碱用于 酯交换合成碳酸二甲酯
}

\author{
廖云辉, b, 李 枫 ${ }^{\mathrm{a}, *}$, 代 金金, 赵 宁 ${ }^{\mathrm{a}, \mathrm{c}}$, 肖福魁 ${ }^{\mathrm{a}, \mathrm{c}, \#}$ \\ a 中国科学院山西煤炭化学研究所煤转化国家重点实验室, 山西太原030001 \\ ${ }^{b}$ 中国科学院大学, 北京 100049 \\ “国家煤基合成工程技术研究中心，山西太原030001
}

摘要: 碳酸二甲酯(DMC)是一种环境友好型绿色化学品, 可作为甲基化和羰基化试剂用于取代传统剧毒的硫酸二甲酯和光 气. 另外, DMC具有良好的溶解性能, 可用于高级溶剂; DMC分子中具有高的氧含量, 可用作汽油添加剂来提高汽油的辛 烷值; DMC还可用作聚碳酸酯的原料. 随着人们环保意识的不断增强, DMC的生产和应用呈现出巨大的吸引力和市场潜 力. DMC合成方法主要有光气法、甲醇氧化羰化法、尿素醇解法及酯交换法等. 酯交换法具有反应条件温和、产率高等 优点, 是目前工业制备DMC的主要方法. 研究发现, 相对于酸性催化剂, 碱性催化剂更有利于酯交换法合成DMC. 金属氧 化物催化剂具有活性高、热稳定性高及可连续重复回收利用等优点, 因而引起了广泛关注. CaO对于酯交换合成DMC反应 具有良好的催化活性, 但其稳定性差. 因此, 通常采用复合金属氧化物来促进 CaO的分散, 并增加金属间相互作用以防止 $\mathrm{CaO}$ 流失. 研究发现, 经炦烧后的 Mg-Al, Ca-Al和Ca-Mg-Al催化剂对于酯交换反应具有高的活性和稳定性. 此外, 通过碱性 稀土金属( $\mathrm{La}, \mathrm{Ce}$ 和Y)的引入可以修饰催化剂上的碱性位点, 从而调变催化剂的碱性.

本文合成了一系列以 Ca-M-Al (M = Mg, La, Ce, Y)层状双氢氧化物为前驱体的固体碱催化剂, 将其用于甲醇与碳酸丙 烯酯酯交换合成DMC. 通过X射线衍射、热重分析、红外光谱、X射线光电子能谱、电感耦合等离子体、 $\mathrm{CO}_{2}$ 程序升温脱 附和 Hammett指示剂对催化剂进行了表征. 研究发现, 各催化剂的活性高低依次为: $\mathrm{Ca}-\mathrm{Y}-\mathrm{Al}<\mathrm{Ca}-\mathrm{Al}<\mathrm{Ca}-\mathrm{Ce}-\mathrm{Al}<$ Ca-La-Al < Ca-Mg-Al, 这与催化剂表面总碱量相一致. 通过 $\mathrm{Mg}$ 和 $\mathrm{La}$ 的引入, 催化剂表面出现了超强碱性位. 其中, $\mathrm{Ca}-\mathrm{Mg}-\mathrm{Al}$ 催化剂表面具有最高的 $(\mathrm{Ca}+\mathrm{Mg})$ : $\mathrm{Al}$ 原子比, 从而导致催化剂表面产生更多的不饱和 $\mathrm{O}^{2-}$ 离子, 因而具有最高的碱 性位数量. 此外, 通过 $\mathrm{Mg}, \mathrm{La}, \mathrm{Ce}$ 和 $\mathrm{Y}$ 的引入, 催化剂的重复使用性能得到了提高. 特别是 $\mathrm{Ca}-\mathrm{Mg}-\mathrm{Al}$ 催化剂, 在10次循环后 仍保持着高的活性, 且其结构没有发生显著变化, 表明其稳定性较高, 因此该催化剂在非均相催化中具有高的应用价值. 关键词: Ca-M-Al层状双氢氧化物; 固体碱; 酯交换反应; 碳酸二甲酯

收稿日期: 2017-07-11. 接受日期: 2017-08-15. 出版日期: 2017-11-05.

*通讯联系人. 电话: (0351)4049612; 传真: (0351)4046129; 电子信箱: lifeng2729@sxicc.ac.cn

\#通讯联系人. 电话: (0351)4041153; 传真: (0351)4046129; 电子信箱: xiaofk@sxicc.ac.cn

基金来源：山西省自然科学基金(201601D102006); 山西省煤基重点科技攻关项目(MD2014-09, MD2014-10).

本文的电子版全文由Elsevier出版社在ScienceDirect上出版(http://www.sciencedirect.com/science/journal/18722067). 